\title{
A Probe Into the Online Teaching Mode of College English During the Period of Prevention and Control of the Novel Coronavirus Epidemic
}

\author{
You Ruihua \\ School of Languages and Culture Communications, Xi'an Ming De Institute of Technology, Xi'an, Shaanxi, China \\ 158655751@qq.com
}

\begin{abstract}
This paper probes into the online teaching mode of College English based on the teaching practices during the period of prevention and control of the novel Coronavirus epidemic by setting up a core online College English teaching course on ChaoXing Learning Platform, with Ding talk and Tencent classroom as its main teaching means. This kind of teaching mode can make full use of various resources from different free open learning platform. By adopting this kind of flexible and diverse teaching mode, College English teachers can maximize the efficiency of College English teaching.
\end{abstract}

Keywords : College English, online teaching, ChaoXing Learning Platform

\section{疫情防控期间大学英语线上教学模式的探索}

\author{
游瑞华 \\ 西安明德理工学院语言文化传播学院, 西安, 陕西, 中国 \\ 158655751@qq.com

\section{摘要} \\ 疫情防控特殊背景下，按照 “停课不停教、停课不停学” 要求, 针对大学英语教学实际, 积极探索线 \\ 上教学模式, 搭设以 “超星学习通” 为主、钉钉视频会议和腾讯课堂为辅的教学平台, 充分利用丰富 \\ 的资源, 采取灵活多样的教学方法, 最大化地完成了大学英语的教学任务, 对基于多平台共用的大学 \\ 英语线上教学模式进行了探索。
}

关键字: 大学英语, 线上教学, 超星学习通

\section{1. 前言}

2017 年教育部制定的《大学英语教学指南》提出, “各高校应充分利用信息技术, 积极创建多元的教学与 学习环境”, “要密切关注移动学习理论的最新发展, 有 条件的高校可以设计和构建 “移动英语学习平台”, 凸 显现代学习方式的自主性、移动性、随时性等特点” ${ }^{[1]}$ 。 在现代信息技术发展和 “互联网+教育” 的大趋势下, 综合应用移动互联网、云计算、大数据、人工智能和多 媒体等技术的大学英语线上教学得到广泛应用, 成为英 语教学的新模式和语言学习的新范式。新冠肺炎疫情的 爆发, 对我国经济社会发展和生产生活秩序带来了严重 的负面影响, 高校的各项工作尤其是教学工作也受到了 极大的冲击。疫情防控期间, 根据各级教育部门 “停课 不停教、停课不停学” ${ }^{[2]}$ 要求, 我们结合大学英语课程
特点，积极探索线上教学实践，运用信息技术手段，采 取以 “超星学习通” 为主、钉钉视频会议和腾讯课堂为 辅的多平台共用教学模式, 发挥资源丰富的优势, 灵活 教学方法, 注重教学质效, 较好地完成了《大学英语 4》 （李荫华主编，上海外语教育出版社，以下简称为《大 学英语 4》) 的教学任务, 同时也是一次大学英语线上教 学的有效探索实践。

\section{2. 立足 “早”，讲协作，全力做足教学准备}

新冠肺炎疫情的发生, 使线上成为了教学的主阵地, 但开展线上教学面临着 “组织难度大、管理责任重、协 调要求高、效果把控难” 等困难, 给学校、教师和学生 都带来了不同程度的考验。按照 “停课不停教、停课不 停学” 的要求, 着眼 “准备时间短、教学任务重” 的实 际，必须深刻认识开展线上教学的重大意义，准确把握 
疫情防控期间的教学安排和具体要求, 早筹划, 早准备, 早行动, 精心部署, 注重协作, 做好思想上、能力上、 课程上的全方位准备, 确保大学英语线上教学随时实施、 高效展开。

\section{1. 统一思想强责任担当}

长期以来传统的以面对面授课为主的线下教学占 主导地位, 因疫情影响线上教学走上了前台, 变成了主 角, 这既是疫情条件下开展教学的应急之举, 也是拓展 教学方式的实践探索, 更是落实“教育信息化 2.0 行动” 的务实之策。必须从思想上高度重视疫情防控期间的线 上教学, 摒弃短见, 克服偏见, 消除畏惧心理和抵触情 绪, 从立德树人的高度, 认识线上教学、适应线上教学、 组织线上教学, 从为人师表的角度, 担起教书育人之责, 化身传道授业 “主播”, 推进 “三全（全员、全过程、 全方位）育人 ${ }^{[3]}$ ”。面对疫情防控期间居家办公的实际, 创建起办公微信群、QQ 群等, 畅通沟通渠道, 搭设学习 平台, 架起合作桥梁, 确保组织领导到位、方案传达到 位、业务学习到位, 确保大学英语线上教学的思想统一、 行动一致。

\section{2. 组织培训补能力短板}

工欲善其事, 必先利其器。教学平台犹如课堂, 熟 练操控平台是做好大学英语线上教学的重要保证。针对 教师对教学平台使用生疏、线上教学经验缺乏的实际, 提前做好线上教学系统的操作培训, 尤其是对新技术应 用水平有限的一线教师的培训 ${ }^{[4]}$, 全面提升教师线上教 学的能力素养。一方面, 本着 “急需急学, 急用急练” 的原则, 邀请平台客服人员讲解平台使用方法, 介绍主 要功能模块, 传授操作方法技巧, 采取边讲解边演示、 边操作边练习的方法, 尽快熟知平台功能, 尽早掌握操 作流程, 将平台打造成大学英语的教学利器。另一方面, 认真分析线上教学和线下教学的异同点, 科学认知大学 英语与其他课程线上教学的不同要求, 加强线上教学研 讨, 总结线上教学特点, 深研线上教学规律, 尤其是疫 情防控条件下的大学英语线上教学的实用方法和有效 举措, 采取以网络交流的形式互谈心得分享经验, 帮助 广大教师理清教学思路, 掌握教学技巧, 为大学英语线 上教学的开展打下坚实基础。

\section{3. 团结协作备精品课程}

课程准备是线上教学的关键点, 必须紧扣教学特点、 紧贴学生实际, 充分发挥平台优势, 合理设置课堂环节, 优化整合教学内容, 确保教学条理分明、效果显著。课 程设计上, 注重顶层设计, 结合平台特点, 与教学目标 对接, 同教学任务齐步, 将《大学英语 4 》课程分为 5 个单元, 每单元进行 4 小节讲解, 每小节分课前、课中、 课后等 3 个环节, 增强课程框架的合理性和使用的高效
性。发挥教师共同体作用，教师各司其职各尽其能，分 单元分模块撰写讲义、制作 PPT, 集中力量备课，集智 攻关解难, 最大程度调动教师的积极性, 发挥教师的创 造性，齐心协力将线上课程打造成 “精品课”，团结合 作使线上平台创建为 “新讲台”; 实施网上预授课，每 一单元挑选 1 名教师实施线上教学试讲, 其余教师担当 学生角色, 同时测试 “讲”与 “听”、“播”与 “看”, 将平台系统调整至最佳, 功能掌握到最熟, 不带故障使 用平台, 不带疑惑开展教学, 有效促进大学英语线上教 学有序展开。

\section{3. 注重 “活”, 求创新, 全心做好教学实施}

疫情防控期间（截至 5 月 8 日），全国 1454 所高校 开展在线教学; 103 万名教师在线开出了 107 万门课程, 合计 1226 万门次课程; 参加在线学习的大学生共计 1775 万人, 合计 23 亿人次 ${ }^{[5]}$ 。可以说, 疫情防控期间 开展的线上教学, 总体规模大, 参与师生多, 不同院校、 不同专业、不同课程在种类繁多的教学平台（截至 2 月 20 日教育部高等教育司发布疫情防控期间支持高校在 线教学的课程资源平台和技术平台共 37 家 $^{[6]}$ )选择上也 不尽相同。教学平台的差异和教学方法的不同，使得线 上课堂更加丰富多样, 没有固定的模式和统一的形式, 必须注重创新, 紧密联系实际, 在 “活” 字上下功夫, 搭活教学平台, 用活教学资源, 灵活教学方法, 以高效 的平台、丰富的资源和有效的方法推进精准施教, 推动 线上教学提质增效。

\section{1. 多平台共用}

受网络速度、终端设备、平台功能等因素的影响, 单一的平台难以满足线上教学的全部需求, 可以搭建 “以 “超星学习通” 为主, 钉钉视频会议和腾讯课堂为 辅” 的多个平台共用的综合线上教学平台系统, 构建多 维高效、功能互补的教学平台。将 “超星学习通” 作为 课程在线授课、学习和在线教学管理实施的主平台, 钉 钉视频会议、腾讯课堂为辅助平台, 既能动态监控学生 大学英语的日常学习 ${ }^{[7]}$, 充分发挥 “超星学习通” 建课 细致全面、处理素材多样、编辑功能丰富的优势, 又能 利用钉钉视频会议进行语音、视频的随时沟通，最大程 度降低线上教学缺乏教室空间感的制约，另外，兼具线 上签到、举手、答题、测验等丰富功能且操作简单的腾 讯课堂, 也是主平台异常情况下较好的备选教学平台。 多平台共用的线上教学平台, 能较好地完成知识要点的 讲授、主题讨论的开展和要点测验的组织等, 最大化地 完成教学任务, 打造可容性强、互动性好的高效线上教 学课堂。

\section{2. 多资源共享}

资源丰富是线上教学最大的优势。突出本校化、原 
创性和实用性 ${ }^{[8]}$, 建设内容丰富、英语特色鲜明的线上 教学资源库。结合大学英语课程特点, 分析研判教学任 务, 按照教学要求录制线上直播课程, 制作授课 PPT, 设计课堂测验试题, 编写单元测验试卷, 形成以“录课、 课件、试题” 为主的教材类基础资源; 充分利用疫情防 控期间超星学习通示范教学包、中国大学慕课等多个教 育平台资源开放的优势, 分类整合与课程单元主题相关 的慕课、微课, 辅助线上教学的实施, 形成与课程结合 紧密、以 “名师授课、专家讲座” 为主的课程类辅助资 源; 深度挖掘网络资源, 遴选 “BBC 纪录片” “你好, 中 国”等英语类人文地理、自然科学、文化历史、影视名 作等音视频资料, 形成以 “开阔视野、强化素质”为主 的进阶类拓展资源。多资源的共享增强了课堂的吸引力 和趣味性, 教师要依据不同课程进度和学生个体差异, 制定合理的学习目标和特定的学习任务, 以任务促进学 习, 以问题引发思考, 有目的地引导学生用好丰富的资 源，共享丰富的资源带来的便利。

\section{3. 多方法共促}

摒弃 “线上教学就是直播讲解或录播课程” 的错误 认识, 采取 “直播/录播+互动答疑” 的教学模式, 综合 运用 “讲授法、讨论法、探究法” 等教学方法, 在互动 与启发中完成线上课程的讲授与练习, 帮助学生梳理知 识点, 解析疑难点。直观的讲解、实时的互动和恰当的 引导, 能最大程度牵引学生课堂上的专注力, 激发学生 课堂参与的热情, 督促学生深入地思考。针对大学英语 线上教学的特殊性, 利用任务驱动法、自主学习法在教 学环节设置一定数量的问题点、安排相应的任务, 通过 设问解疑, 激发学生求知的欲望和积极的思维, 引导学 生主动探寻答案, 完成布置的任务, 培养自主学习的习 惯; 结合智能终端特点, 采取网络分享、素材穿插、设 置回看等, 便于学生结合自身实际, 因人而异, 展开学 习, 查漏补缺, 拓展进阶。

\section{4. 务求 “实”, 抓反馈, 全面做细教学考评}

教学反馈是教学活动中重要的环节, 也是影响教学 质量的重要因素。正如美国心理学家加涅所说, “学习 的每一个动作, 如果要完成, 就需要反馈, 反馈是学生 学习的重要条件”。大学英语线上教学更需要全面准确 的反馈, 实施学生与老师的同步考评, 求实求细, 将反 馈结果作为掌握线上教学效果和调整线上教学策略的 重要依据, 推进教学质量提升, 推动教学目标落实, 促 进教学过程形成完整闭环。

\section{1. 考勤随机化}

强化责任意识，任课教师、辅导员和班干部共同参 与线上教学考勤, 形成齐抓共管的合力, 确保考勤正规 高效。班干部及时通知班级人员按课程安排进入线上课
堂; 任课教师坚持课前组织签到打卡，课中随机点名、 随时调看学生视频、随堂在线提问等, 多策并用, 多管 齐下，力求克服迟到、早退及课上开着终端设备 “开小 差” 的思维跑路情况发生; 辅导员不定时检查出勤记录, 并根据请假情况, 及时核查缺勤原因, 确保学生的出勤 率。

\section{2. 测验多样化}

针对大学英语线上教学效果难掌握的实际, 坚持以 考促教, 以考促学, 以适当的测验检验教学效果, 巩固 教学成果。内容上, 根据授课实际, 注重过程化的考核, 全程设置题目类型不同的练习, 实时检测学生的线上学 习情况; 结合授课进度, 在平台上布置课后作业, 设置 章节测验小卷, 将随堂练与阶段测相结合, 单项考与综 合考相结合, 全面准确掌握学生的线上学习状况。方法 上, 发挥平台自动批阅功能, 实现对 “听力、阅读” 等 客观题的批改; 利用小程序、群功能等, 采取传照片、 展视频的形式, 实现对 “翻译、写作” 等主观题的检验 考核。

\section{3. 督导常态化}

成立院系教学督导组, 推行常态化督导, 负责教学 的全面监督。教学督导组成员不定期进入平台管理后台, 查阅教师课程准备及进展情况, 学生作业完成及学习情 况; 深入线上课堂, 进入班级群, 开展巡课听课, 检查 平台运行、课堂秩序、师生互动、教学质量等, 推动在 线教学落地落实、高质高效; 每周组织教学督导总结会, 反馈督导发现的问题, 提出合理的意见建议, 促进教学 改进提高。

\section{4. 反馈制度化}

形成定期反馈机制, 准确掌控教学情况, 为合理评 估教学效果以及实时调整教学方法提供参考。注重反馈 的全面性, 既要包含教师 “教” 的反馈, 也要包括学生 “学” 的反馈, 以提高反馈信息的准确度和普遍性。坚 持每堂课后任课教师填写 “线上教学反馈表”, 实时记 录课堂教学, 反馈学习情况; 每周利用教学平台讨论留 言功能, 及时收集学生的学习疑惑和具体的实际困难, 做好学生的答疑和解难工作; 每月利用教学平台组织问 卷调查, 收集意见建议, 及时调整教学内容, 改进教学 方法, 确保大学英语线上教学顺利进行, 与线下课程同 质等效。

\section{5. 结语}

随着信息技术的飞速发展，网络成为人们交流沟通、 协同工作、获取信息、开展决策的重要工具 ${ }^{[9]}$, 开展线 
上教学正是基于信息技术条件下教学模式的革新, 相比 线下教学有其无可比拟的优势和得天独厚的便利, 疫情 防控期间大规模的应用更是有力地推动了线上教学的 探索与实践。实践证明, 着眼大学英语教学实际, 通过 搭建以 “超星学习通” 为主、钉钉视频会议和腾讯课堂 为辅的教学平台, 辅以丰富的资源, 以灵活的方法施教, 以准确的反馈促教, 是开展大学英语教学的有效途径, 能较好地完成大学英语 “听、说、读、写、译” 综合技 能提升的教学任务, 推动复合型人才的培养, 具有一定 的实践意义和推广价值。

\section{REFERENCES}

[1] Ministry of Education of the People's Republic of China. (2017) College English Curriculum Requirements. http://www.360doc.com/content/17/0203/00/413468_6262 10661.shtml.

[2] Novel Coronavirus Epidemic Prevention and Control Office of Ministry of Education. (2020) Guidance on the Organization and Management of Online Teaching in Colleges and Universities during the Period of Prevention and Control of the Novel Coronavirus Epidemic. http://www.moe.gov.cn/srcsite/A08/s7056/202002/t202002 05_418138.html.

[3] State Council, Central Committee of the Communist Party of China. (2017) Opinions on Strengthening and Improving the Ideological and Political Work in Colleges and Universities under the New Situation. http://www.gov.cn/xinwen/2017-02/27/content_5182502.ht $\mathrm{m}$.

[4] Gao, Yu. (2020) New Teaching Mode in the Future Will Rely on Online Advantages. https://news.gmw.cn /2020-04/28/content_33790708.htm.

[5] Ministry of Education of the People's Republic of China. (2020) Creating a New Peak of Online Teaching in Colleges and Universities in Practice. http://www.moe.gov.cn/fbh/live/2020/51987/mtbd/202005/ t20200518_455656.html.

[6] Wu, Yan. (2020) Coping with Crisis, Turning Crisis into Opportunity and Actively Seeking Change to Build an International Online Teaching Platform and Curriculum Resources. China University Teaching , 4:4-16, 60.

[7] Wang, Jing. (2019) An Empirical Research on the Mobile Teaching Platform of College English in Application-Oriented Universities-Based on Fan Ya Network Teaching Platform and Superstar Learning APP. Journal of Zhaotong University,41:109-114.

[8] Lin, Lanfang. (2019) A Study on the Reform of
College English Teaching from the Perspective of Hybrid Teaching Method. Journal of Changchun Institute of Technology (Social Sciences Edition),20:110-113.

[9] Wang, Shuiguo. (2017) Rain Classroom: The Wisdom Teaching Tool in the Context of Mobile Internet and Big Data. Modern Educational Technology, 27:26-32. 